\title{
A survey and analysis of BER over different Gaussian noise
}

\author{
Mukesh Bhaskar* and Anil Khandelwal \\ Department of Electronics and Communication, VNS Group of Institutions, Bhopal, India
}

\section{(C)2017 ACCENTS}

\begin{abstract}
Additive white Gaussian noise (AWGN) is used as a variant attribution for different random process. It can be added with different noise to make the system intrinsic. Rayleigh fading is used to show the propagation model which can represent nonlinearity and scattering. This combination can be more effective when it can be tested with different modulation and amplitude. It is also effective for the noise reduction. So the combined transmission system with orthogonal frequency division multiplexing (OFDM) and multiple inputs and multiple outputs (MIMO) will be effective. So the main focuses of this survey paper is to finding the capability with different modulation and improve the error ration by calculating the impact with the help of bit error rate (BER).
\end{abstract}

\section{Keywords}

OFDM, MIMO, BER, AWGN, Rayleigh channel.

\section{Introduction}

OFDM is a fruitful strategy to soothe the medium correspondence. OFDM is a repeat division multiplexing (FDM) plan utilized as a progressed multi-carrier change method $[1,2]$ in a manner of speaking OFDM is repeat division multiplexing of multi-bearers which are orthogonal to each other i.e. they are put accurately at the nulls in the regulation spectra of each other. This makes OFDM appallingly more compelling [3]. In OFDM data is isolated into a couple parallel data streams or sub-channels, one for each sub conveyor which are orthogonal to each other notwithstanding the way that they cover appallingly Each sub-transporter is controlled with a normal regulation plan, (for example, QAM or PSK) at a low picture rate keeping up total data rates like conventional single-transporter change plots in the same transmission limit.

In today's circumstance MIMO is to a great degree accommodating with the mix of OFDM structure. Abusing the flexibility of MIMO systems remembering the final objective to have high data rates is an especially charming investigation topic for future booking arrangement arranges and their applications. Distinctive data different yield (MIMO) systems offer much greater channel limit over standard single-data single-yield structure.

*Author for correspondence
As of various transmit Algorithms have been delivered to experience as far as possible in the MIMO systems [4,5].Furthermore, in MIMO structures, resulting to selecting the social event of customers with the at present most prominent achievable rates managed by a package scheduler in without fail opening, we need to delegate them to the transmitter's radio wires in such a course, to the point that we can finish the best throughput in the system. Grouped qualities strategies, for instance, space-time coding have gotten a ton of thought in view of their ability to give higher unearthly profitability than routine single-data single-yield frameworks [6-9]. While applying this methodology in a repeat specific channel, a space-time equalizer is required at the recipient to compensate for the impedance [10].

This multipath spread reasons optional time dispersing, tightening, and stage development, known as obscuring, in the got signal [11,12]. Obscuring is achieved by deterrent between two or more types of the transmitted sign which connected at the authority at to some degree unmistakable times [13]. DSCDMA system has the upsides of extending as far as possible nearby the resistance against staying [1416]. In multi-customer CDMA structures, various access interface (MAI) is seen as one of the standard wellsprings of execution debasement. Flexible isolating techniques have been adequately used to level the direct and in this way lessen the MAI in the DS-CDMA structure $[17,18]$. 


\section{Related work}

In 2011, Dubey et al. [19] proposed a modernize SLM (MSLM) plan to lessen the PAPR by using the psyche boggling sign separate into certifiable and whimsical parts and independently arrange progression various honest to goodness and nonexistent bit of complex banner then select slightest PAPR indication of real and whimsical and these are solidify. The proliferation show fulfills incredible PAPR, which is an in number contender for Future remote correspondence. In 2011, George A. Ropokis et al. [20] present a symptomatic bit error rate (BER) execution examination of three perceive and-forward (DaF) courses of action under a run of the mill framework. More especially, as far as possible and association adaptable arrangements are focused on, which differentiate in the way the decision on the transmitted picture is sent from the hand-off to the destination. The examination is finished for a single hand-off $\mathrm{DaF}$ transmission tradition and considers the picture decision botches that may happen at the exchange. Clear close structure demonstrative BER expressions are deduced for each one of the three arrangements, which are completely affirmed by entertainments. In 2012, Mohamed Samir et al. [21] propose a change to the execution of a direct sequence code division multiple access (DS-CDMA) system by utilizing an adaptable channel as a part of the region of unmistakable staying routines. To fight the impact of such staying, the flexible channel utilizes three adaptable estimations which are the variable step-size affine projection (VSS-APA) count, the generalized normalized gradient descent (GNGD) figuring, and the generalized square-error-regularized (GSER) NLMS computation. According to the inventors these counts have the advantages of snappy meeting, low predictable state mean squared mix-up and the ability to upgrade the BER execution of the standard CDMA structure, in the region of multi-way, various passageway, and unmistakable staying signs. Results exhibit that the VSS-APA defeats distinctive estimations in the region of surge staying. While in the region of midway band staying the GSER-NLMS flexible channel gives the best execution. In 2014, Le et al. [22] show a precise piece mistake rate estimation strategy for QPSK CO-OFDM transmission taking into account the likelihood thickness capacity of the got QPSK images. Creators had been thought about some known methodologies, including information supported and non-information helped blunder vector size, they demonstrate that the proposed technique offers the most exact appraisal of the framework execution for both single channel and wavelength division multiplexing QPSK CO-OFDM transmission frameworks. In 2014, Zahed et al. [23] exhibited a diagnostic way to deal with decide the effect of recurrence counterbalance, timing jitter and added substance white Gaussian clamor (AWGN) on the BER execution of a MC-DS-CDMA framework over a Rayleigh Fading Channel. The examination built up the pdf (likelihood thickness capacity) at the collector considering joined impact of blurring, timing jitter and Doppler recurrence counterbalance and so on with maximal proportion consolidating plan. The expression for the restrictive BER adapted on a given timing blunder and blurring is determined and the normal BER is assessed in the vicinity of multiple access interference (MAI) and inter-carrier interference (ICI). The execution results are assessed numerically regarding SINR and BER considering framework parameters like number of clients, number of sub-transporters. The outcome demonstrates critical decay in SINR and BER execution because of blurring alongside the adjustments in parameters. In 2015, Kumar et al. [24] proposed a wavelet based SCFDMA for investigating BER execution. Investigation is did utilizing distinctive wavelets and diverse adjustment plans under AWGN channel. This investigation will demonstrate that the diminishment in BER happens by utilizing wavelet change as a part of SCFDMA. Along these lines wavelet based SCFDMA gives preferable BER execution over that of DFT based SCFDMA. In 2015, Jie et al. [25] proposed a MIMO-OFDM system, which is the combination of MIMO and OFDM technology for the high data transmission rate usability. They have suggested that MIMO-OFDM with STBC has excellent performance against Multi-path effects and frequency selective fading, the BER and the coding complexity is low. Their simulation model of MIMOOFDM system which is based on STBC is analysed on different transmission performances under different channels. In [26] authors has raised the same issues and depicted that it can be solved with different channel model.

\section{Problem formulation and analysis}

The attributes of remote sign changes as it goes from the transmitter radio wire to the beneficiary reception apparatus. These qualities rely on the separation between the two radio wires, the ways taken by the sign and the earth around the way. When all is said in done, the force profile of the got sign can be acquired by convolving the force profile of the transmitted sign with the drive reaction of the channel. Convolution in time area is proportionate to duplication in the recurrence space. In this manner, 
the transmitted sign $x$, after engendering through the channel gets to be

$$
y(f)=H(f) x(f)+n(f)
$$

Channel response is denoted by $\mathrm{H}$ (f), and the noise is indicated by $\mathrm{n}$ (f). The items situated around the way of the remote sign mirror the sign. Some of these reflected waves are likewise gotten at the collector. Since each of these reflected signs takes an alternate way, it has an alternate plentifulness and stage. Channel estimation can be performed in three ways. They are preparing based channel estimation, visually impaired channel estimation and semi visually impaired channel estimation. In preparing based channel estimation, known images are transmitted particularly to help the recipient's channel estimation calculations. Here, preparing images or pilot condition that are known from the earlier to the recipient, are multiplexed alongside the information stream for channel estimation. In a visually impaired channel-estimation system, the beneficiary must decide the channel without the guide of known images. The visually impaired channel estimation is completed by assessing the measurable data of the channel and certain properties of the transmitted signs. Albeit higher-data transmission proficiency can be acquired in visually impaired procedures because of the BER. It is the figuring speaks to the rate of bit mistakes happening in an advanced information stream, for example, Internet or computerized phone signals. Bit blunders happen because of commotion or twisting in some piece of the circuit that causes a " 1 " to be gotten as a " 0 " and the other way around. The presence of bit blunders requires that mistake registering techniques be manufactured with correspondence frameworks to recognize such issues. Computerized transmissionstream quality can be assessed by contrasting the quantity of bits transmitted every second and the rate of those bits that must be retransmitted because of mistakes. Continuous observing of the BER remains a critical undertaking in keeping up top notch computerized correspondences. This below Table 1 represent power spectrum density(PSD) or energy spectral density (ESD), which is a positive real function of a frequency variable associated with a stationary stochastic process, or a deterministic function of time, which has dimensions of power per hertz $(\mathrm{Hz})$, or energy per hertz. So there is the need of reduction of BER with the channel mode representation.
Table 1 Welch power spectral density estimate

\begin{tabular}{lll}
\hline S.NO & Frequency & Spectral density \\
\hline 1 & $0-50$ & -110 \\
2 & $50-100$ & $-120-(-110)$ \\
3 & $100-150$ & -110 \\
4 & $150-200$ & -40 \\
5 & $200-250$ & $-100-(-115)$ \\
6 & $250-300$ & $-110-(-115)$ \\
7 & $300-350$ & $-115-(-105)$ \\
\hline
\end{tabular}

The below Table 2 represents spectral density of digital signal which is generated from discrete signal from the message signal from the review.

Table 2 Power spectral density

\begin{tabular}{lll}
\hline S.NO & Frequency & Spectral density \\
\hline 1 & $0-0.4$ & $0-1.4$ \\
2 & $0.4-0.8$ & 0 \\
3 & $0.8-1.2$ & 0 \\
4 & $1.2-1.6$ & $0-1.3$ \\
5 & $1.6-1.2$ & $1.3-2$ \\
\hline
\end{tabular}

The below Table 3 represents received signal in front of receiver side. It includes noise with addition of transmitted signal from the transmitter. We have to control the transmission distortion and temperature also be considered.

Table 3 Received signal

\begin{tabular}{lll}
\hline S.NO & Frequency & $\begin{array}{l}\text { Spectral density } \\
\text { received }\end{array}$ \\
\hline 1 & $0-0.4$ & $-8-+8$ \\
2 & $0.4-0.8$ & $-7-(-6)$ \\
3 & $0.8-1.2$ & $-7-(-6)$ \\
4 & $1.2-1.6$ & $-5-(-7)$ \\
5 & $1.6-1.2$ & $-6-(-7)$ \\
\hline
\end{tabular}

We have assumed that the transmitter sends digital information by use of $\mathrm{M}$ signals waveforms $\{\mathrm{sm} \mathrm{g}$ $\{(\mathrm{t})=1,2, \ldots, \mathrm{M}\}$. Each waveform is transmitted within the symbol interval of duration $T$, i.e. $0 \leq t \leq T$. The channel is assumed to corrupt the signal by the addition of white Gaussian noise where $n(t)$ denotes a sample function of AWGN process with power spectral density. Frequency comparison is shown in Table 4. Result comparisons are shown in Table 5.

Table 4 Corrupted signal

\begin{tabular}{lll}
\hline S.NO & Frequency & Corrupted signal \\
\hline 1 & $0-0.4$ & Both axis \\
2 & $0.4-0.8$ & Both axis \\
3 & $0.8-1.2$ & Both axis \\
4 & $1.2-1.6$ & Both axis \\
5 & $1.6-1.2$ & Both axis \\
\hline
\end{tabular}


Table 5 Comparative study

\begin{tabular}{|c|c|c|c|c|}
\hline S.NO & Reference & Method used & Results achieved & Parameters \\
\hline 1 & {$[24]$} & $\begin{array}{l}\text { Wavelet based } \\
\text { SC-FDMA }\end{array}$ & BER performance has been analysed based on 64QAM. & $\begin{array}{l}\text { 16-QAM, } \\
\text { QAM }\end{array}$ \\
\hline 2 & [27] & $\begin{array}{lr}\text { AWGN } & \text { and } \\
\text { Rayleigh } & \text { Fading } \\
\text { Channel } & \end{array}$ & $\begin{array}{l}\text { The BER framework will be able to cope the modulation } \\
\text { variations from 16,32,64 and 128 QAM. }\end{array}$ & $\begin{array}{l}\text { 16-QAM, } \\
\text { QAM, } \\
\text { QAM, } \\
\text { QAM- }\end{array}$ \\
\hline 3 & {$[28]$} & $\begin{array}{l}\text { Multiple } \\
\text { Modulation } \\
\text { Techniques }\end{array}$ & $\begin{array}{l}\text { In this modulation schemes used the BER performance of BPSK } \\
\text { was found to be better than QPSK, } 16 \text { PSK and } 16 \text { QAM for the } \\
\text { same SNR. }\end{array}$ & $\begin{array}{l}\text { 16-QAM, } \\
\text { QAM }\end{array}$ \\
\hline 4 & [29] & $\begin{array}{l}\text { Digital } \\
\text { Modulation } \\
\text { Schemes } \\
\text { With and Without } \\
\text { OFDM Model }\end{array}$ & $\begin{array}{l}\text { The multiple digital modulation schemes effective when paired } \\
\text { with OFDM, like BPSK, } \\
\text { QPSK, 8PSK, 16QAM, 32QAM, 32QAM, 64QAM, and it is } \\
\text { more robust to noise and ISI. }\end{array}$ & $\begin{array}{l}\text { 8PSK,16-QAM, } \\
\text { 32-QAM, 64- } \\
\text { QAM }\end{array}$ \\
\hline 5 & {$[30]$} & $\begin{array}{l}\text { Evaluation of } 64 \\
\text { QAM OFDM } \\
\text { System }\end{array}$ & $\begin{array}{l}\text { The SER calculation is accomplished in this paper for the means } \\
\text { of modelling the decision variable at the receiver as a particular } \\
\text { case of quadratic form D in complex Gaussian random variables. } \\
\text { Lastly comparative study of SER performance of } 64 \text { QAM- } \\
\text { OFDM simulated \& } 64 \text { QAM-OFDM theoretical under AWGN } \\
\text { channel has been done. }\end{array}$ & 64-QAM \\
\hline 6 & {$[31]$} & $\begin{array}{l}\text { Digital } \\
\text { Modulation } \\
\text { Schemes on } \\
\text { Additive White } \\
\text { Gaussian Noise, } \\
\text { Line of Sight and } \\
\text { Non Line of } \\
\text { Sight Fading } \\
\text { Channels }\end{array}$ & $\begin{array}{l}\text { The evaluation of three digital modulation schemes i.e. 16-QAM, } \\
\text { 64-QAM and 16-DPSK in terms of Bit Error Rate (BER) is } \\
\text { performed on Additive White Gaussian Noise (AWGN), Line of } \\
\text { Sight (Rician) and Non Line of Sight (Rayleigh) Fading Channels } \\
\text { has been performed. Among the three digital modulation schemes, } \\
\text { 16-QAM is showing better performance as compared to 64-QAM } \\
\text { and 16- DPSK. }\end{array}$ & $\begin{array}{l}\text { 16-QAM, } \\
\text { QAM }\end{array}$ \\
\hline
\end{tabular}

\section{Conclusion and future work}

In view of the above investigation we can suggest that AWGN and Rayleigh channel with STBC can be productive in diminishing BER rates. It is more proficient on account of related conjunction of the transmitter and the beneficiary sign. It can be better with white timing jitter and opposite quick Fourier change too. The transmission fluctuation will be successful in the event that it is related with distinctive parameters. In the future work a framework should be designed to accept channel variability with the error rate reducibility mechanism.

\section{Acknowledgment}

None.

\section{Conflicts of interest}

The authors have no conflicts of interest to declare.

\section{References}

[1] Frederiksen FB, Prasad R. An overview of OFDM and related techniques towards development of future wireless multimedia communications. In RAWCON radio and wireless conference 2002 (pp. 19-22). IEEE.
[2] Bingham JA. Multicarrier modulation for data transmission: An idea whose time has come. IEEE Communications Magazine. 1990; 28(5):5-14.

[3] Wang Z, Ma X, Giannakis GB. OFDM or singlecarrier block transmissions? IEEE Transactions on Communications. 2004; 52(3):380-94.

[4] Trivedi S, Raeen MS, Pawar SS. BER analysis of MIMO-OFDM system using BPSK modulation scheme. International Journal of Advanced Computer Research. 2012; 2(5):219-26.

[5] Xia P, Giannakis GB. Design and analysis of transmitbeamforming based on limited-rate feedback. In vehicular technology conference 2004 (pp. 1653-7). IEEE.

[6] Paramita S, Singh SS, Mohanta J. Time and frequency synchronization in OFDM system. International Journal of Advanced Computer Research. 2014; 4(16):856-65.

[7] Gupta MV, Tiwari MR. Performance analysis and simulation result of MC-CDMA for AWGN channel and Raleigh based on SNR/BER. International Journal of Advanced Computer Research. 2011; 1(1):13-17.

[8] Rathore M, Tanwar P. Reduction of co-channel interference in transmit/receive diversity (TRD) in MIMO System. International Journal of Advanced Computer Research. 2012; 2(3):13-17.

[9] Gupta P, Singh UP, Richhariya V. Analysis and comparison of the 4-PSK and 8-PSK STTC over 
Mukesh Bhaskar et al.

Rayleigh fading channels for determining performance. International Journal of Advanced Computer Research.2012; 2(5):142-9.

[10] Zhou S, Wang Z, Giannakis GB. Quantifying the power loss when transmit beamforming relies on finite-rate feedback. IEEE Transactions on Wireless Communications. 2005; 4(4):1948-57.

[11] Tarokh V, Seshadri N, Calderbank AR. Space-time codes for high data rate wireless communication: performance criterion and code construction. IEEE Transactions on Information Theory. 1998; 44(2):74465.

[12] Foschini GJ. Layered space-time architecture for wireless communication in a fading environment when using multi-element antennas. Bell Labs Technical Journal. 1996; 1(2):41-59.

[13] Anitha K, Sujatha BK. FPGA implementation of high throughput digital QPSK modulator using verilog HDL. International Journal of Advanced Computer Research. 2014; 4(14):217-22.

[14] Foschini GJ, Gans MJ. On limits of wireless communications in a fading environment when using multiple antennas. Wireless Personal Communications. 1998; 6(3):311-35.

[15] Telatar E. Capacity of multi-antenna Gaussian channels. European Transactions on Telecommunications. 1999; 10(6):585-95.

[16] Daksh JK, Mohan R, Sharma S. Performance analysis with space-time coding in MIMO-OFDM systems with multiple antennas. International Journal of Advanced Computer Research. 2013; 3(10):126-9.

[17] Choubey R, Mohan R, Sharma S. A survey of BER performance of generalized MC DS-CDMA system. International Journal of Advanced Computer Research.2013; 3(10):130-33.

[18] Daksh JK, Mohan R, Sharma S. A survey of performance analysis in MIMO-OFDM systems. International Journal of Advanced Computer Research. 2013; 3(10):91-4.

[19] Dubey AK, Khandagre Y, Kushwaha GR, Hemnani K, Tiwari R, Shrivastava N. PAPR reduction in OFDM by using modernize SLM technique. In recent trends in wireless and mobile networks 2011 (pp. 397-405). Springer Berlin Heidelberg.

[20] Ropokis GA, Rontogiannis AA, Berberidis K. BER performance analysis of cooperative $\mathrm{DaF}$ relay networks and a new optimal DaF strategy. IEEE Transactions on Wireless Communications. 2011; 10(4):1044-9.
[21] Samir M, Shaheen EM, El Wahab AA. Performance analysis of DS-CDMA system using fast adaptive filtering under different jamming techniques. In international conference on engineering and technology 2012 (pp. 1-6). IEEE.

[22] Le ST, Blow KJ, Mezentsev VK, Turitsyn SK. Bit error rate estimation methods for QPSK CO-OFDM transmission. Journal of Lightwave Technology. 2014; 32(17):2951-9.

[23] Zahed MI, Majumder SP. Performance analysis of MC-DS-CDMA in the presence of carrier frequency offset and timing jitter over Rayleigh fading channels. In international conference on computer and information technology 2014 (pp. 1-5). IEEE.

[24] Kumar N. BER analysis in Wavelet based SC-FDMA for LTE uplink transmission. In 2015 fifth international conference on advanced computing \& communication technologies 2015 (pp. 437-40). IEEE.

[25] Jie Z, Liang LI, Jin LI. Performance analysis of space time block code in MIMO-OFDM systems. In international conference on communication software and networks 2011 (pp. 13-16). IEEE.

[26] Rawat S, Kakde B. A survey on BER performance analysis in AWGN and rayleigh fading channel. International Journal of Advanced Technology and Engineering Exploration. 2015;2(7):111-6

[27] Rawat S, Kakde B. Efficient BER performance analysis in AWGN and Rayleigh Fading Channel with range modulation. International Journal of Advanced Technology and Engineering Exploration (IJATEE). 2015; 2(7):97-103.

[28] Sharma P, Singh B, Tanwar PS. A review in multiple modulation techniques 16 and 64 QAM MIMOOFDM BPSK-QPSK-PSK SYSTEM. International Journal of Electrical, Electronics and Computer Engineering. 2014; 3(1):196-200.

[29] Usha SM, Nataraj KR. BER performance of digital modulation schemes with and without OFDM model for AWGN, Rayleigh and rician channels. International Journal of Science and Research. 2015; 4(11):330-5.

[30] Namdeo S, Rani R. Designing and performance evaluation of 64 QAM OFDM systems. IOSR Journal of Electronics and Communication Engineering.2013; 5(6):97-105.

[31] Anand P, Gupta A, Bhagat S. Bit error rate assessment of digital modulation schemes on additive white Gaussian noise, line of sight and non-line of sight fading channels. International Journal of Engineering Science Invention. 2014; 3(8).6-10. 